\title{
Macro Demand Spatial Approach (MDSA) at Spatial Demand Forecasting for Transmission System Planning
}

\author{
Sudarmono Sasmono, Ngapuli Irmea Sinisuka, Mukmin Widyanto Atmopawiro, and Djoko Darwanto
}

School of Electrical Engineering and Informatics, InstitutTeknologi Bandung, Indonesia

\begin{abstract}
Macro Demand Spatial Approach (MDSA) is an approach introduced in long time electricity demand forecasting considering location. It will be used at transmission planning and policy decision on electricity infrastructure development in a region. In the model, MDSA combined with qualitative approach and quantitative approach as mixed method. QA used to determine main development area and supporting area in region. This method is used to prove the hypothesis that the observed transmission service area are not homogeneous.Main development area is an area with industrial domination as a driver of economic growth. Whilst, supporting area is an area with residential domination that supporting economic growth at main development area.Hence, the electricity demand driver variables are different for type of electricity consumer at different spatial characteristics. The variables have no significant effect can be reduced by using PCA. The results of PCA should be validated with the results of QA. Generated models formed from the variables generated by PCA. The generated models tested to assess whether it fit with the actual data. Range of interval confidence level used as fit criteria. At the case study, generated model for main development areas and supporting area in Southern Sumatra Regionas a part of Sumatra System is still in the range of confidence level. Thus, MDSA can be proposed as alternative approach on demand forecastingat transmission planning that considering location.
\end{abstract}

Keywords: Spatial electricity demand forecasting; macro demand spatial approach; principal component analysis; main development area; transmission planning

\section{Introduction}

Transmission expansion planning is built based on electricity demand and load analysis. Despite this, electricity demand on which to base the development of the transmission is not only in magnitude but including where demand is required in an electrical system and when it necessary needs. These characteristics indicate that the analysis of the electricity demand in the transmission system planning requires different approach than the analysis of the electricity demand in the generation planning. These characteristics requires also knowledge of the direction of development of the transmission service area.However, in some cases on master plan of the transmission expansion conducted by the power company, forecasting load which current use regarded not sufficiently anticipate direction of development area. Approach to electricity demand forecasting which in accordance with the characteristics of the transmission system planning and also consider direction of development area is electricity demand forecasting that consider the space. A particular transmission service area can be seen as a space with different characteristics compare other transmission service area.

Electricity demand forecasting that consider factors such space was first introduced by Van Wormer in 1954. It presented in the Van Wormer paper entitled "Some Aspects of the Distribution Area Load Geometry".The paper was published in Power Apparatus and Systems Volume 73, No. 2, 1954, page 1343-1349.Principally, Van Wormer proposes an approach to the development of the electrical power system are optimal with respect to the geometry of the load area[26]. The term geometry load area subsequently changed to spatial load area. Both of these terms refer to a particular area was the focus of attention of power system planners.Furthermore, spatial load forecasting method developed by Lee Willis and followed by other researchers. [17].

Received: April $28^{\text {th }}, 2014$. Accepted: May $23^{\text {rd }}, 2015$ 
Spatial load forecasting was developed by Lee Willis and other researchers used for distribution system planning, small area and short term forecasting. Because of such properties, spatial load forecasting driver used is the change in land use. Direction of past land-use change modeled to obtain correlation between land use and the load. The model developed with different variations of them by Carreno [3], [4] Chouw [6], Tao Hong [25], Jain [15] and Melo [18], [19].

The characteristic of spatial load forecasting for transmission planning are long-term and broader area. Thus, it is not possible to use land use change as drivers. Generally, drivers used for long-term forecasting of electricity demand is economic growth. Strong correlation between electricity demand and economic growth has become rule in electricity economic subject [7]. Hence, the alternative driver that can be used in spatial load forecasting for transmission planning is economic variables. According to direction of development area, the transmission service area define as central area of economic growth and the supporting area of economic growth [21]. The central area of economic growth define as main development area[9], [22], [23], and other area define as supporting area.

The use of economic growth as a driver in electricity demand caused the load in each spatial area cannot be directly predicted. At the early stage, the predicted results are electricity demand in electricity energy unit. To get the load in each spatial area required additional predictive load duration curve and load factor based on the direction of economic growth and development as well as the directions of development in each region characteristics. They are qualitative. Thus, it required an integrative approach of quantitative analysis and qualitative analysis. This approach is known as a mixed method approach [8].This approach differs from the long-term load forecast developed by Hyndman [14]. Hyndman approach model emphasizes the probability of peak load incidence in the future which is based on past conditions.

The approach on correlation between economic growth and the electricity demand in main development area and supporting area as a basis for transmission planning is a causality approach. This approach is more robust than the time series approach or an intelligent system approach which has been developed recently [2], [10], [11]. When it applied to transmission service area which have different characteristics according to its direction of development, the approach used requires different causality model between each area[1], [12], [13], [28].The approach was introduced as macro demand spatial approach (MDSA). The approach was use mixed method approach.

The paper describes an important part of the development of MDSA using mixed method. It is combinequalitative approach and quantitative approach. Qualitative approach use principal component analysis (PCA), while qualitative approach use Qualitative analysis (QA). QA results should be in line with the results of the PCA.Such terms is condition to use mixed methods approach. Condition where QA and PCA results in line referred "triangulation".QA used to determine whether the region studied is main development area or supporting area. PCA is used as a basis to establish a mathematical model for each spatial unit. Through this method obtained a number of economic variables that affect electricity demand for each sector in each spatial region. The variables that affect every load sector in each unit spatial is assumed different.The assumption is in accordance with the assumption that transmission service area is heterogeneous. The approach was different with another PCA applied in forecasting. Another approach proposed by other researcher was neural network combined with PCA [5], PCA as basis for MIX SVM [27] and principal component regression analysis. [29]

Furthermore, mathematical model is formed from another results of the PCA.The mathematical model used is the linear model. Tests carried out to assess whether the model in accordance with the actual data. The concordance of PCA results and QA results indicate that mixed methods can be applied to the spatial load forecasting.Moreover, the final results indicate that the MDSA can be recommended as an alternative methods of spatial load forecasting for transmission planning. 


\section{The Concept of Macro Demand Spatial Approach (MDSA)in Transmission Planning}

Generally the approach to transmission planning can be divided into 2 approaches. The first approach is known as "regional balance". The regional balance approach is an approach that sees the electricity demand in a certain spatial area should be met by energy sources in such spatial area.Based on regional balance approach, transmission line developed generally are short distance with high voltage level.The second approach is known as 'supply balance' approach. The supply balance approach is approach that sees the electricity demand in a certain spatial area filled with optimal system scenarios. Such scenario opens opportunities deliver power from distant power plant to center load.Based on such approach, transmission line developed generally are longdistance with extra high voltage level.

In a country where not every spatial unit has adequate sources of primary energy, 'regional balance' approach cannot be used.'Supply balance' approach is more proper and widely used. Optimal transmission planning with supply balance approach requires load information i.e. Load centre location and its electricity demand. Such information is needed to answer the question where, when and how much power will distributed in system. As already described in the introduction, information such as location of electricity load centre, magnitude of electricity load and others information which is used to answer the question where, when and how much power will delivered in system, refers to a wide area. In many cases of practical planning done by the power company such as in Indonesia, the master plan of transmission planning for extensive area requires electricity demand forecasting which is not only relying on a number of historical data. Electricity demand forecasting for electricity transmission planning was expected to also accommodate the direction of regional development. Basically, spatial load forecasting concept can meet those requirements. However it takes some development concept to answer those needs.

Spatial load forecasting on transmission planning is unique. Investment in transmission is a long term investment. Options transmission line built shall able meet the needs of long-term power transmission. It is considering investment in transmission line expensive. Therefore, such condition leads spatial load forecasting for transmission planning is long-term forecasting. Additionally, transmitted power through transmission line is power with a large quantity. Such power is generally served for wide area. Therefore, spatial load forecasting for transmission planning has a wider spatial units than spatial units that have been defined in traditional spatial load forecasting. Thus, changes in land use cannot be used as drivers on spatial electricity demand forecasting for transmission planning.

Spatial approach used to obtain the optimal planning requires the establishment of appropriate spatial units with transmission service area. Establishment and direction of the development of spatial units that has proximity character is basically built from qualitative information. Thus, spatial electricity demand forecasting for transmission planning require qualitative analysis and qualitative approaches.

\section{A. Mixed Method on Macro Demand Spatial Approach (MDSA)}

Models and concepts proposed to address these issues is a model and the concept of Macro Demand Spatial Approach (MDSA). The concept is using a combined approach between the qualitative and quantitative approaches. The combined approach is known as a mixed method approach. This approach is a third approach which complements the previous two approaches, qualitative and quantitative. Mixed method approach appear to answer the research issues that are not sufficiently solved with only a qualitative approach or quantitative approach. In spatial electricity demand forecasting for transmission planning, the establishment of spatial units and its development direction have qualitative characteristics. Results of spatial electricity demand forecasting needs to be unvarying with the direction of the development of spatial units. Thus, the final interpretation is a model which already combines quantitative analysis and qualitative analysis 
Characteristics of MDSA model are shown in table 1.As shown in table 1, the combine technique uses technique of quantitative model validated by qualitative models. In the mixed method approach, such merging techniques known as "triangulation". Triangulation in a mixed method approach is the approach which conduct the process of getting and analyse data of different but complementary to study the same topic, so it can meet best understanding of the research problem. Sub triangulation techniques used in MDSA is validating quantitative data model. Flow diagram of validating quantitative data model in MDSA as mixed method approach is shown in figure 1 . In accordance with flow diagram as shown in figure 1 , MDSA modelling started with equal process among quantitative approaches and qualitative approaches.

Table 1. Characteristics of MDSA model

\begin{tabular}{|l|l|}
\hline \multicolumn{1}{|c|}{ Component } & \multicolumn{2}{c|}{ Description } \\
\hline Quantitative & Mathematical model of electricity demand forecasting. \\
\hline Qualitative & $\begin{array}{l}\text { Modelling of spatial area of electricity transmission service in } \\
\text { accordance with the direction of the development of such spatial region. }\end{array}$ \\
\hline Weight & $\begin{array}{l}\text { Mathematical model of electricity demand forecasting validated by } \\
\text { modelling of spatial area of electricity transmission service in } \\
\text { accordance with the direction of the development of such spatial region } \\
\text { Quantitative approach and qualitative approach have an equal weight in } \\
\text { the modelling. }\end{array}$ \\
\hline
\end{tabular}

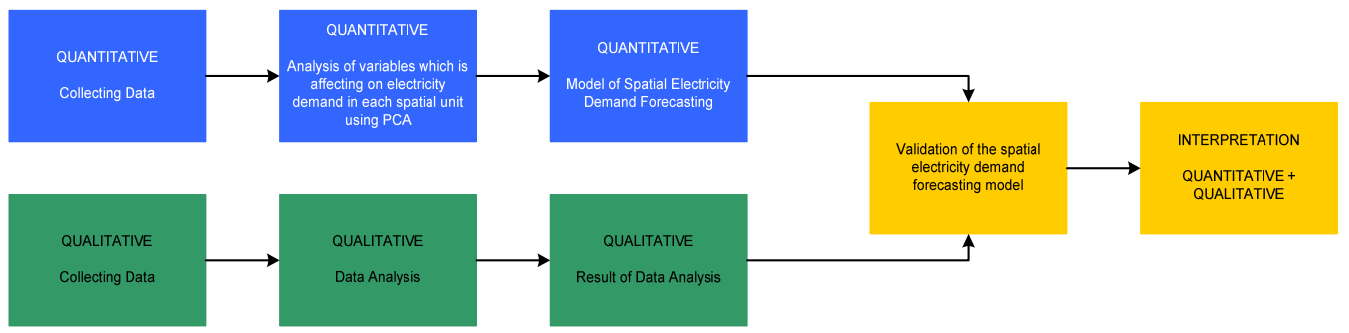

Figure 1. Flowdiagram of validatingquantitative data model in MDSA as mixedmethodapproach

\section{B. Qualitative Approach}

In a qualitative approach, a number of documents that indicate the direction of development in the area of spatial observed were collected and analyzed. Qualitative analysis (QA) is used to determine formation of the spatial unit, $s$. As already describe in introduction, there are 2 types of spatial unit as area served by electrical power system i.e. main development areas (se) and supporting development areas (ss).Results of QA is a grouping of transmission service area that observed as spatial unit se and spatial unit ss.Economic variables that affect electricity demand in spatial unitse would be similar. Also, economic variables that affect electricity demand in spatial unit ss would be similar. Thus, the results of QA can be used to validate the mathematical model of the electricity demand forecasting in each service area transmission that observed.

\section{Quantitative Approach}

In the quantitative approach, historical data collection of electricity demand in the spatial unit that observed is conducted. Additionally, it also collected a number of historical data of variables on macro and microeconomics which in theory could affect electricity demand in spatial unit that observed. At the stage of the analysis in quantitative approach, deep analysis is conducted to determine macroeconomic and micro economic variables that surely affects 
electricity demand in spatial unit that observed. PCA (principal component analysis) is used for such purposes.

PCA is a concept based on the concepts of linear algebra and geometry of algebra. The goal of PCA is to compute the most meaningful basis to re-express a noisy data set. The hope is that this new basis will filter out the noise and reveal hidden structure. Thus, PCA is about finding relationship whole sets of variables and finding the strength of those relationship. PCA is used in quantitative approach of MDSA because PCA is a simple, non-parametric method with minimal effort to reduce a complex data set to a lower dimension. In simple, PCA can be expressed as a data reduction technique. Specific data, $y$, is expressed as a function of a set of data, $a, b, c, d$ and so on. Data $y$ are dependent variables, while the data $a, b, c$, and $d$ and so on are independent variables. There is a possibility that there is a correlation between the independent variables. Such correlations are called coupling or noise. By using PCA, coupling and noise can be avoided, then intact function that fully indicates the function between the dependent variable $y$ with the independent variables $a, b, c, d$ and so on can be obtained.

Hypothetically, in the formation of the spatial unit s, can be stated that in each spatial unit, independent variables that influence electricity demand is unique.PCA assist selecting independent variables which significantly affecting electricity demand.

There are two steps in determining the main driver variables at both spatial units, following: (1).Variables which hypothesized affect electricity demand in both spatial unit defined base on references, (2). Selection of significant variables affect electricity demand using principal component analysis (PCA).

Generally, variables that affect the electricity demand in each sector are different. Variables thought to affect the electricity demand at each sector in Indonesia is shown in Table 2. These variables are based on the assumptions used in the modeling of electricity demand projections by Stoll [24].

Table 2. Variables thought to affect the electricity demand at each sector in Indonesia

\begin{tabular}{|l|l|c|}
\hline \multirow{4}{*}{ SECTOR } & \multicolumn{1}{|c|}{ VARIABLES } & SYMBOL \\
\hline \multirow{4}{*}{ RESIDENTIAL } & Population & $v_{1}$ \\
\cline { 2 - 3 } & Household & $v_{2}$ \\
\cline { 2 - 3 } & GDP & $v_{3}$ \\
\cline { 2 - 3 } & GDP per capita & $v_{4}$ \\
\cline { 2 - 3 } & Residential Connected Power & $v_{5}$ \\
\hline \multirow{3}{*}{ COMMERCIAL } & GDP on Commercial Sector & $v_{6}$ \\
\cline { 2 - 3 } INDUSTRY & Commercial Connected Power & $v_{7}$ \\
\hline \multirow{3}{*}{$\begin{array}{l}\text { PUBLIC } \\
\text { FACILITY }\end{array}$} & GDP on Industrial Sector & $v_{8}$ \\
\cline { 2 - 3 } & Industrial Connected Power & $v_{10}$ \\
\cline { 2 - 3 } & Regional Revenue & $v_{11}$ \\
\hline
\end{tabular}

PCA is non-parametric approach which relies on large $\mathrm{N}$ series to get consistent estimates. In this step, large $\mathrm{N}$ series of dependent variables analyzed to get common factors.

In general, the mathematical model has general equation following:

$$
\mathrm{yt}=\alpha \mathrm{pt}+\beta \mathrm{qt}+\ldots+\gamma \mathrm{rt}
$$

Where, $y=$ electricity demand in year $-t ; p, q, r=$ variables affect electricity demand in year$t ; \alpha, \beta, \gamma=$ coefficient. As explain before, the goal of principal component analysis is to identify 
the most meaningful basis to re-express a data set. The hope is that this new basis will filter out the noise and reveal hidden structure. The explicit goal of PCA is to determine: "the dynamics are along the x-axis." In other words, the goal of PCA is to determine that ^x, i.e. the unit basis vector along the $\mathrm{X}$-axis, is the important dimension [8].

Assuming the independent variables $\mathrm{X}, \mathrm{P}, \mathrm{Q}$ and so on are a set of data, then equation (1) can be transformed into the form of a matrix $V(\mathrm{n} \times \mathrm{p})$ which satisfies the equation (2):

$$
Y=\delta^{T} v=\delta_{1} v_{1}+\delta_{2} v_{2}+\ldots+\delta_{p} v_{p}
$$

Where $\delta=\left(\delta_{1}, \delta_{2}, \ldots, \delta_{p}\right) T$ are a column vector of weights with $\delta_{1}{ }^{2}+\delta_{2}{ }^{2}+. .+\delta_{p}{ }^{2}=1$. Find $\delta$ after maximize the variance of the projection of the observations on the $Y$ variables as following:

$$
\operatorname{Var}(\delta \mathrm{T})=\delta \mathrm{T} \operatorname{Var}(\mathrm{V}) \delta \text { is maximal }
$$

The matrix $C=\operatorname{Var}(X)$ is the covariance matrix of the $X i$ variables, where:

$$
\mathrm{C}=\left(\begin{array}{ccc}
\mathrm{v}\left(\mathrm{v}_{1}\right) \mathrm{c}\left(\mathrm{v}_{1}, \mathrm{v}_{2}\right) & \ldots \ldots & \mathrm{c}\left(\mathrm{v}_{1}, \mathrm{v}_{\mathrm{p}}\right) \\
\mathrm{c}\left(\mathrm{v}_{1}, \mathrm{v}_{2}\right) \mathrm{v}\left(\mathrm{v}_{2}\right) & \ldots \ldots & \mathrm{c}\left(\mathrm{v}_{2}, \mathrm{v}_{\mathrm{p}}\right) \\
\mathrm{c}\left(\mathrm{v}_{1}, \mathrm{v}_{\mathrm{p}}\right) \mathrm{c}\left(\mathrm{v}_{2} \mathrm{v}_{\mathrm{p}}\right) & \ldots \ldots & \mathrm{v}\left(\mathrm{v}_{\mathrm{p}}\right)
\end{array}\right)
$$

The direction of $\delta$ is given by the Eigen vector $\gamma_{1}$ corresponding to the largest Eigen value of matrix $C$. The second vector that is orthogonal (uncorrelated) to the first is the one that has the second highest variance which comes to be the Eigen vector corresponding to the second Eigen value. Thus, generally, if value of the correlation matrix between the dependent variable with the independent variable being tested close to 1 then it showed a significant correlation between them.

Another result of PCA are new variables $\mathrm{Yi}$. The new variables are linear combination of the original variables ( $v i)$ following:

$$
\mathrm{Y}_{\mathrm{i}}=\mathrm{a}_{\mathrm{i} 1} \mathrm{v}_{1}+\mathrm{a}_{\mathrm{i} 2} \mathrm{v}_{2}+\ldots \mathrm{a}_{\mathrm{ip}} \mathrm{v}_{\mathrm{p}} ; \mathrm{i}=1 . . \mathrm{p}
$$

The new variables $Y i$ are derived in decreasing order of importance. They are defined as 'principal components'. Also, equation (5) is mathematical model used to forecast electricity demand for sector $i$. Established mathematical model was tested with a series of historical data. The test is done to see whether the mathematical model can be used in electricity demand forecasting of each sector $i$. Criteria used is maximum confidence level $=10 \%$. If the difference between the forecasting and the historical data is in the range of $-10 \%$ to $10 \%$ then the mathematical model is fit. In the research, linear model used as model.

\section{Validation and Interpretation}

In the early development of MDSA model, validation and interpretation of quantitative results by qualitative results was done by comparing the results of the electricity demand forecasting model in each transmission service area that observed. Transmission service areas that observed which is categorized as spatial unit se by qualitative analysis will have electricity demand forecasting model with similar forming variables. So it is with transmission service areas which are categorized as spatial unit ss.Despite this, the variables forming electricity demand forecasting models in spatial unit se and ss will be different.Meanwhile in interpretation, it can be shown model of electricity demand forecasting will generalized to every category of spatial units. 


\section{Case Study}

Case study of MDSA was conducted in Southern Sumatera Region (SSR). The region is one of region in Sumatera Electricity Interconnection System (SEIS). Others regions are Central Sumatera and Northern Sumatera. There are 3 electricity subsystem in Southern Sumatera Region. They are South Sumatera Subsystem, Bengkulu Subsystem and Lampung Subsystem. South Sumatera Subsystem serve South Sumatera Provinces, whilst, Bengkulu Subsystem serve Bengkulu Provinces and Lampung Subsystem serve Lampung Provinces, respectively.

The selection of this region as a case study based on the possibility of developing electrical power system that is still open. Moreover, SSR is a vital one in SEIS.Potential of primary energy for electricity generation is abundant in the region.Similarly, the economic development of the region as a buffer to economic growth in the western part of Java Island. Single line diagram of SEIS shown in figure 2.

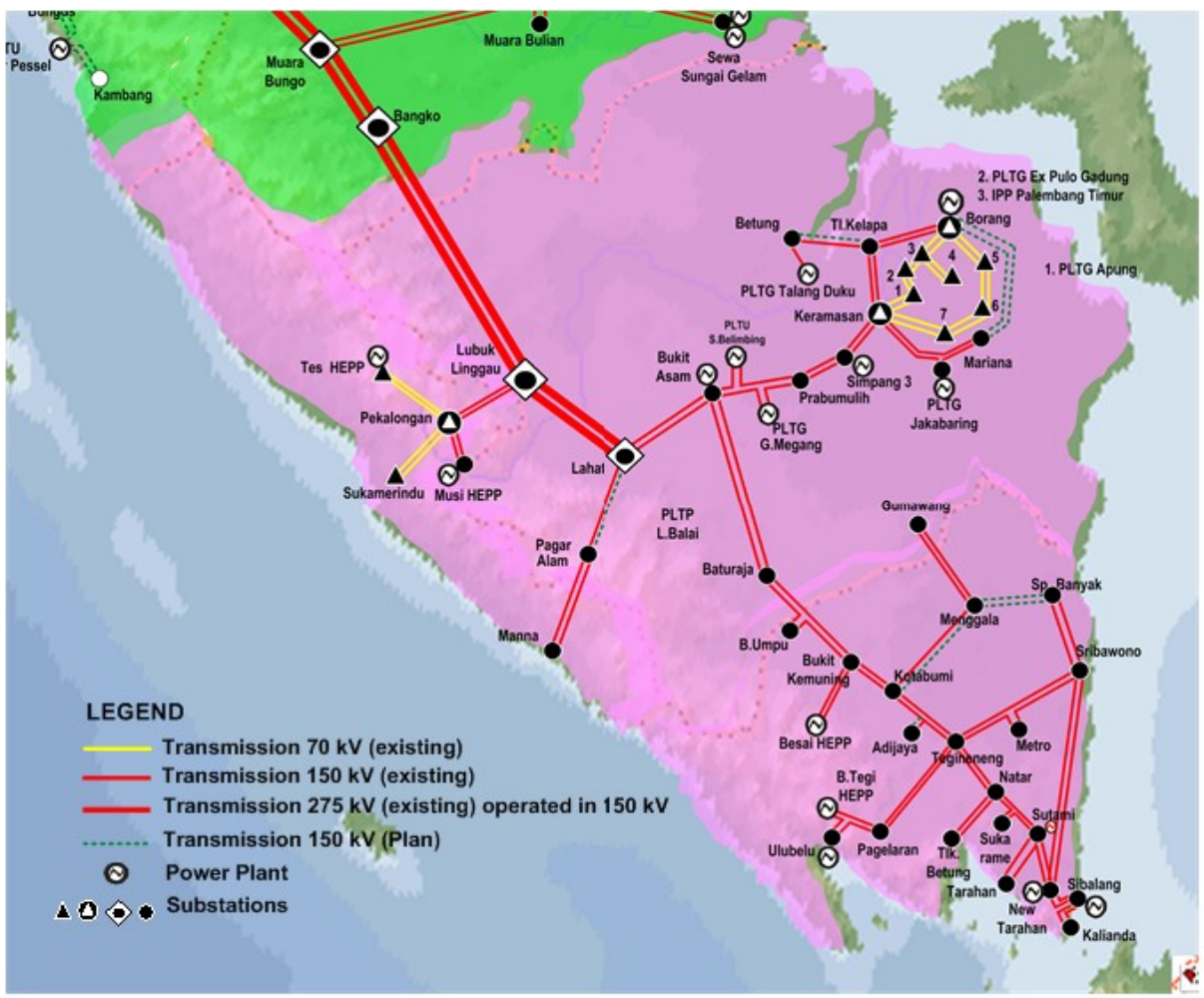

Figure 2. Single Line Diagram of SSR.

Figure 2 shows service area of electricity subsystem, position of power plant, transmission and load in Southern Sumatera Region. Though the administrative area is not always equal to the area of electricity subsystems, but in general the administrative area has similarities with electricity subsystems.Considering the matter, then SSR can divided into 3 spatial units. The unit spatial are South Sumatera, Bengkulu and Lampung.Documents of regional development plan that analyzed is the document of Sumatera development plan as a whole. Selection of development plan documents of Sumatra region is done in order to obtain an integrative assessment of SSR positions on observations of a whole Sumatera. Observation area is basically a subset of the parent region. SSR region which became the area of observation is a subset of Sumatra.

MDSA approach in determining the electricity demand in SSR started with qualitative analysis. Documents used as references to conduct qualitative analysis of spatial electricity 
demand in Sumatera are following: (1). Presidential Decree No. 13/2012 on Spatial and Regional Planning at Sumatera, (2). Document of Master Plan for the Acceleration of Indonesian Economic Development (MP3EI) at Sumatera Corridor [16],[20]. Document review is done to get indications that indicates whether the spatial space observed can be categorized as se or ss. The indications are shown in table 2.

As shown on the table, indication of the center of economic activity in SSR located in South Sumatra and Lampung. While Bengkulu serves as a supporting for center of economic activity. Such indications can also be compared with other qualitative data. The west coast of Sumatra is close to the line of plate collision. This area becomes the area prone to earthquakes. While the east coast is relatively more steady. Having regard to these indications as well as other supporting qualitative data it can be concluded South Sumatra and Lampung meet the characteristics of spatial space se, while Bengkulu meet the spatial characteristics of spatial space $s$.

Table 3. Indications in the spatial space observed based on document review with QA method

\begin{tabular}{|c|c|c|}
\hline \multirow[b]{2}{*}{ Spatial space, $s$} & \multicolumn{2}{|c|}{ Indications According to Document } \\
\hline & $\begin{array}{l}\text { Presidential Decree No. } 13 / 2012 \text { on } \\
\text { Spatial and Regional Planning at } \\
\text { Sumatera }\end{array}$ & $\begin{array}{l}\text { Presidential Decree No. 32/2011 } \\
\text { on Document of MP3EI at } \\
\text { Sumatera Corridor }\end{array}$ \\
\hline South Sumatera & $\begin{array}{l}\text { One of the } 9 \text { National Activity } \\
\text { Centers (NAC) in Sumatera is } \\
\text { Palembang. Palembang is located } \\
\text { in South Sumatra. }\end{array}$ & $\begin{array}{l}\text { Rubber plantations, rubber } \\
\text { processing and rubber downstream } \\
\text { industries. } \\
\text { Coal mining area which has } 45 \% \\
\text { of Indonesia's coal reserves }\end{array}$ \\
\hline Bengkulu & - & - \\
\hline Lampung & $\begin{array}{l}\text { One of the } 9 \text { National Activity } \\
\text { Centers (NAC) in Sumatera is } \\
\text { Bandar Lampung. Bandar } \\
\text { Lampung is located in Lampung. }\end{array}$ & $\begin{array}{l}\text { Development and expansion area } \\
\text { of the steel smelting industry from } \\
\text { Cilegon, Banten } \\
\text { The gate of the national strategic } \\
\text { importance of the Sunda Strait } \\
\text { (KSSN) on Sumatera. }\end{array}$ \\
\hline
\end{tabular}

PCA simulations as quantitative approach were performed using SPSS 19.0 software. The data used in the simulation are the data for each variable on each spatial unit. In this research, spatial unit is province. Thus, the data used is data of South Sumatra, Bengkulu and Lampung at long period. The source of Data are The Statistics of PLN in South Sumatera, Jambi and Bengkulu (S2JB) and The Statistics of South Sumatera, Bengkulu and Lampung.

The total electricity demand $=Y$, electricity demand on residential sector $=Y_{l}$, electricity demand on commercial sector $=Y_{2}$, electricity demand on industrial sector $=Y_{3}$, and electricity demand on public facility $=Y_{4} . Y, Y_{1}, Y_{2}, Y_{3}$ and $Y_{4}$ are dependent variable, whilst $v_{1}, v_{2}$, $v_{3}, v_{4}, v_{5}, v_{6}, v_{7}, v_{8}, v_{9}, v_{10}$ and $v_{11}$ are independent variable. Therefore, table 4 shows result of SPSS simulation for PCA. They are component matrix of the all variables affect $Y_{1}, Y_{2}, Y_{3}$ and $Y_{4}$ in South Sumatera, Bengkulu and Lampung.

As shown in Table 4, independent variables $v_{4}$ thought to affect the dependent variable $y_{1}$ has a coefficient matrix that is close to 0 . This indicates that such variable has no significant effect on the variable $y_{1}$. The results were found on South Sumatra and Lampung. Mean while, in Bengkulu, the value of independent variables $v_{9}$ close to 0 , while the value of the variable $v_{11}$ close to 0.5 . It showed that $v_{9}$ has no significant effect to $y_{3}$, while $v_{11}$ don't have strong enough influence on $y_{4}$.

Variable of $v_{4}$ which has no effect on the variable of $Y_{1}$ is found in South Sumatra and Lampung. According the results of the qualitative analysis, both of such spatial units are grouped as a spatial unit of se. While $v_{9}$ and $v_{11}$ which does not have a significant effect on each variable $y_{3}$ and $y_{4}$ are found in Bengkulu. Furthermore, mathematical models for the three 
units of the spatial formulated based on coefficient correlation matrix between dependent variable to independent variables. The mathematical model is shown in the following equations:

Where $i=s=$ South Sumatera

Table 4. Component matrix of variables though to affect the electricity demand at each sector in SSR

\begin{tabular}{|c|c|c|c|c|}
\hline \multicolumn{2}{|c|}{ Variabel } & \multicolumn{3}{|c|}{ Component Matrix } \\
\hline Dependent & Independent & $\begin{array}{c}\text { South } \\
\text { Sumatera }\end{array}$ & Lampung & Bengkulu \\
\hline \multirow{5}{*}{$Y_{I}$} & $v_{1}$ & 0.966 & 0.991 & 0,994 \\
\hline & $v_{2}$ & 0.966 & 0.966 & 0,959 \\
\hline & $v_{3}$ & 0.958 & 0.992 & 0,995 \\
\hline & $v_{4}$ & 0.018 & 0.193 & 0,993 \\
\hline & $v_{5}$ & 0.881 & 0.996 & 0,995 \\
\hline \multirow{2}{*}{$Y_{2}$} & $v_{6}$ & 0.994 & 0.995 & 0,995 \\
\hline & $v_{7}$ & 0.986 & 0.974 & 0,974 \\
\hline \multirow{2}{*}{$Y_{3}$} & $v_{8}$ & 0.994 & 0.940 & 0,995 \\
\hline & $v_{9}$ & 0.986 & 0.970 & $-0,015$ \\
\hline \multirow{2}{*}{$Y_{4}$} & $v_{10}$ & 0.930 & 0.986 & 0,859 \\
\hline & $v_{11}$ & 0.941 & 0.928 & 0,689 \\
\hline
\end{tabular}

$$
\left\{\begin{array}{l}
Y_{1 \mathrm{~s}}=0.220 v_{1}+0.239 v_{2}+0.271 v_{3}+0.269 v_{5}-25 \\
Y_{2 \mathrm{~s}}=0.337 v_{6}+0.334 v_{7}+1.24 \\
Y_{3 \mathrm{~s}}=0.346 v_{8}+0.338 v_{9}+0.55 \\
Y_{4 \mathrm{~s}}=0.339 v_{10}+0.343 v_{11}-6.49 \\
Y s=Y_{1 \mathrm{~s}}+Y_{2 \mathrm{~s}}+Y_{3 \mathrm{~s}}+Y_{4 \mathrm{~s}}
\end{array}\right.
$$

Where $i=l=$ Lampung

$$
\left\{\begin{array}{l}
Y_{1 l}=0.251 v_{1}+0.245 v_{2}+0.251 v_{3}+0.252 v_{5}-23 \\
Y_{2 l}=0.342 v_{6}+0.335 v_{7}+0.43 \\
Y_{3 l}=0.493 v_{8}+0.507 v_{9}+0.51 \\
Y_{4 l}=0.488 v_{10}+0.212 v_{11}-6.30 \\
Y l=Y_{1 l}+Y_{2 l}+Y_{3 l}+Y_{4 l}
\end{array}\right.
$$

Where $i=b=$ Bengkulu 
Sudarmono Sasmono, et al.

$$
\left\{\begin{array}{l}
Y_{1 b}=0.202 v_{1}+0.198 v_{2}+0.201 v_{3}+0.202 v_{4}+0.196 v_{5}-13 \\
Y_{2 b}=0.500 v_{6}+0.500 v_{7}-0.37 \\
Y_{3 b}=v_{8}-0.09 \\
Y_{4 b}=0.555 v_{10}-0.17 \\
Y b=Y_{1 b}+Y_{2 b}+Y_{3 b}+Y_{4 b}
\end{array}\right.
$$

Test of suitability model conducted by comparing electricity demand forecasting with historical data. Historical data on the period of 6 years from 2006 to 2011 are used in this research. The criteria used is:

$\Delta\left(Y i-Y i^{\prime}\right) \leq 0.1$

Table 5. The test results are shown in table 5, while its description are shown in figure 3

Result of test of suitability model

\begin{tabular}{|c|c|c|c|}
\hline \multirow{2}{*}{$\begin{array}{c}\text { Dependent } \\
\text { Variable }\end{array}$} & \multicolumn{3}{|c|}{$\overline{\Delta\left(\boldsymbol{Y}_{\boldsymbol{\imath}}-\boldsymbol{Y}_{\boldsymbol{}}\right)}$} \\
\cline { 2 - 4 } & South Sumatera & Lampung & Bengkulu \\
\hline $\mathrm{Y}_{1}$ & 0,02 & 0,005 & 0,01 \\
\hline $\mathrm{Y}_{2}$ & 0,03 & 0,1 & 0,02 \\
\hline $\mathrm{Y}_{3}$ & 0,001 & 0,07 & 0,0003 \\
\hline $\mathrm{Y}_{4}$ & 0,02 & 0,03 & 0,1 \\
\hline
\end{tabular}

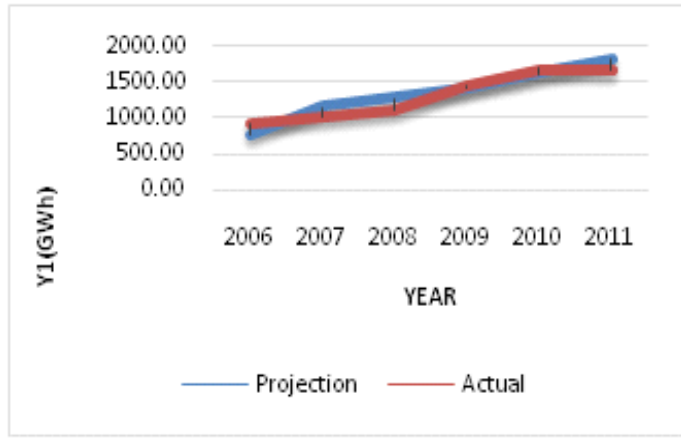

(a). $Y_{1 \mathrm{~s}}$

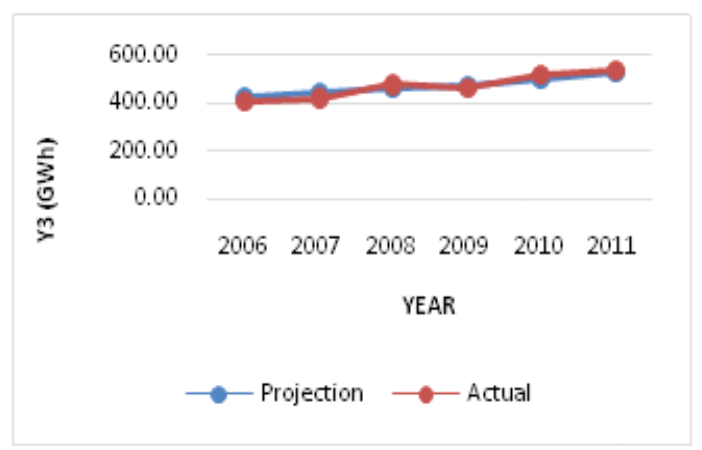

(c). $\mathrm{Y}_{3 \mathrm{~s}}$

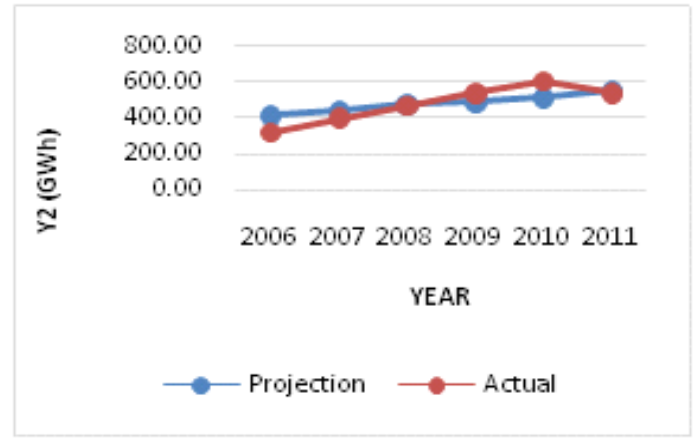

(b). $\mathrm{Y}_{2 \mathrm{~s}}$

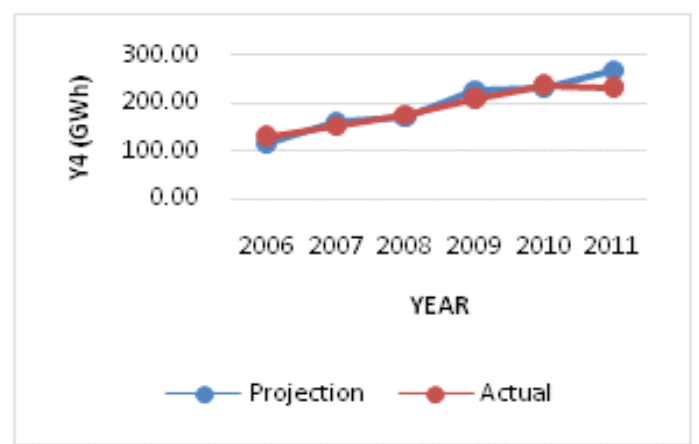

(d). $Y_{4 s}$

(A). South Sumatera 
Macro Demand Spatial Approach (MDSA) at Spatial Demand

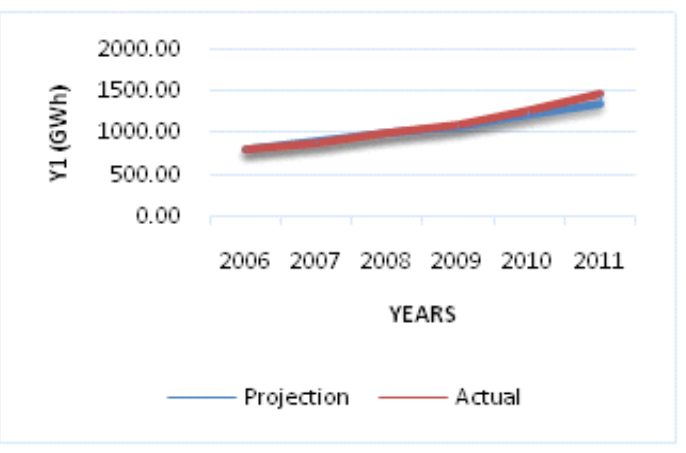

(a). $\mathrm{Y}_{1 l}$

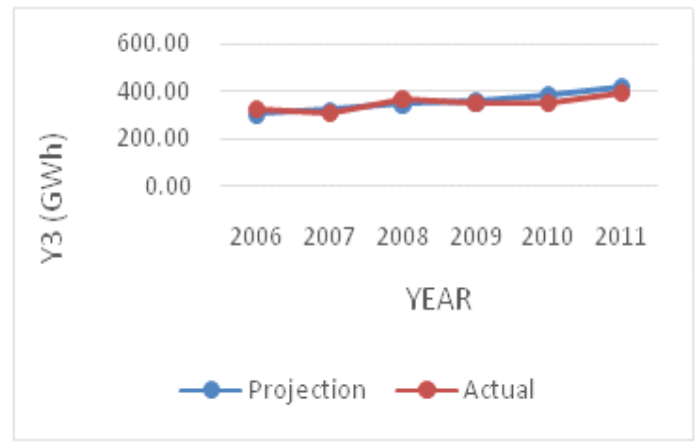

(c). $\mathrm{Y}_{3 l}$

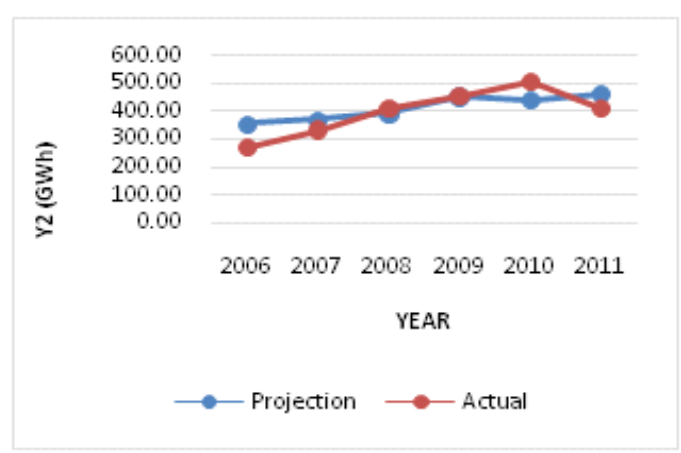

(b) $\mathrm{Y}_{2 l}$

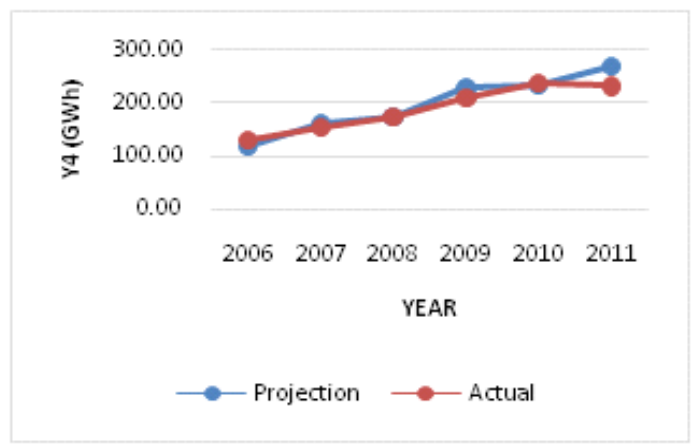

(d). $Y_{4 l}$

(B) Lampung

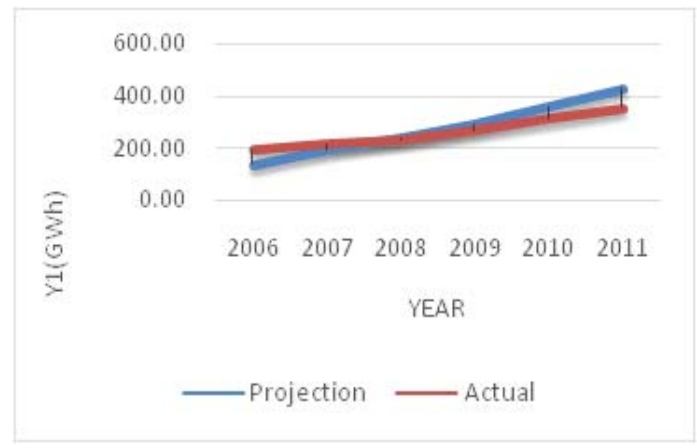

(a) $\mathrm{Y}_{1 b}$

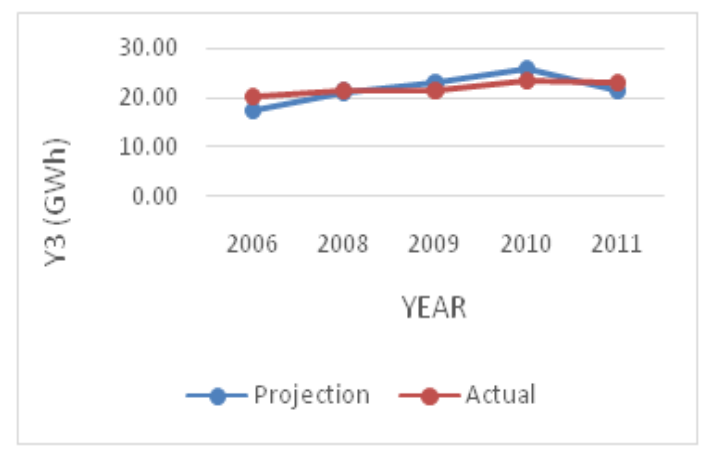

(c). $\mathrm{Y}_{3 b}$

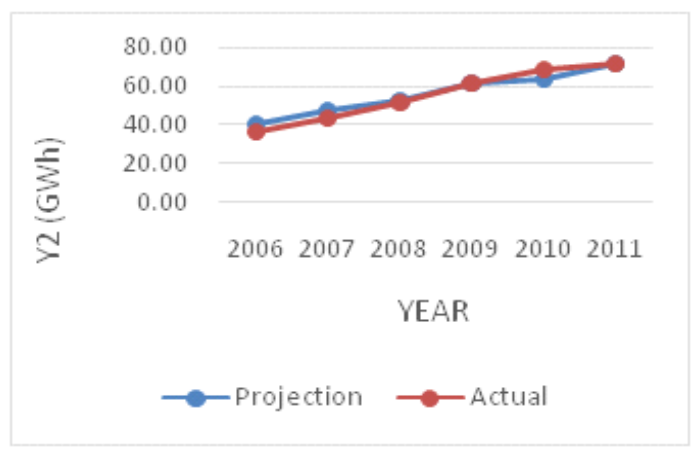

(b). $\mathrm{Y}_{2 b}$

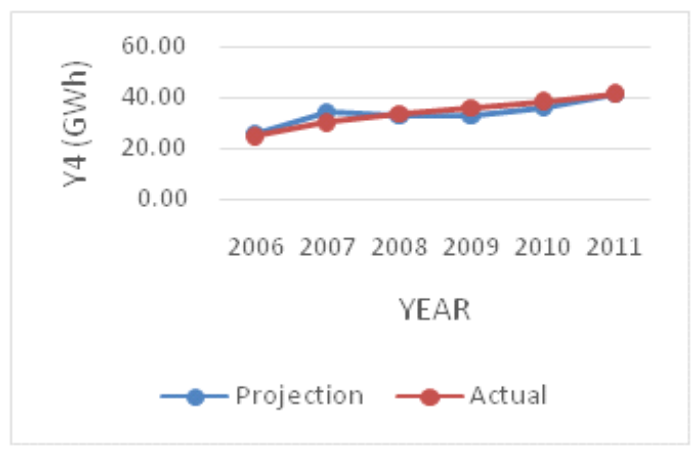

(d). $\mathrm{Y}_{4 b}$

(C). Bengkulu

Figure 3. Thedepiction of modelfit 
Table 5 and Figure 3 shown the value of $\Delta(Y i-Y i$ '). The highest one $(0.1)$ found in the mathematical model of electricity demand forecasting on the industrial sector at Lampung. However, the value still meets the suitability criteria are used. It can be concluded that all the established mathematical model of the value of the correlation coefficient matrix meets the criteria of suitability with historical data. Thus, the mathematical model can be used to forecast electricity demand in transmission service area that observed.

Finally, according to the result of a qualitative analysis, Bengkulu classified as spatial units of ss. Whilst, South Sumatera and Lampung classified as spatial units of se. The forming variables of electricity demand forecasting on South Sumatera and Lampung are similar. It is different with forming variables of electricity demand forecasting on Bengkulu. Thus, the two approach show the consistency between the results of the PCA as quantitative approach and the result of QA as qualitative approach. It means results of quantitative approach is valid.Thus, forming variables of electricity demand forecasting model in both group of such spatial units can be used in other transmission service area.

\section{Conclusions}

Macro Demand Spatial Approach (MDSA) is alternative approach introduced in this study as a spatial approach applied in transmission expansion planning. This approach meets the characteristics of long-term forecasting as the basis for transmission planning.

MDSA model that combines qualitative analysis and principal component analysis showed good forecasting results.It suggests that the model can be used in establishing long-term electricity demand forecasting which based not only on quantitative aspects.

Heterogeneous properties of spatial space which served by electricity transmission system is evidenced by the differences in the variables driver of electricity demand for each sector in each spatial area. The driver variables of electricity demand forecasting model on main development area are similar. Despite this, the driver variables of electricity demand forecasting model of supporting area are different one.

\section{Acknowledgement}

Qualitative analysis in this study has been used in the qualitative analysis of the direction of development as basis for spatial energy demand forecasting in the area of Southern Sumatera Region at "Study of Master Plan Development on Sumatera Electrical System". The study is conducted by PT PLN (Persero) in collaboration with LAPI ITB at 2012 - 2013.

\section{References}

[1]. Al Boody, Ahed, Sedes, Florence, Inglada, Jordi, (2008). "Post-Classification and Spatial Reasoning: New Approach To ChangeDetection for Updating GIS Database“, Proceeding of 3rd International Conference on Information and Communication Technologies, 2008

[2]. Alfares, Hesham K, Nazeeruddin Mohammad, "Electric Load Forecasting; Literature Survey and Classification of Methods", International Journal of System Science, Vol 33, No 1, pp $23-34,2002$.

[3]. Carreno, E. M, Padilha-Fetrin, A, "Spatial Electric Load ForecastingUsing A Local MovementApproach “, UNESP, Ilha Solteira, Brazil, pp 1-5, 2009.

[4]. Carreno, E. M, Padilha-Fetrin, Leal, A.G "Spatial Electric Load Forecasting Using An Evolutionary Heuristic", Revista Controle \& Automacao, Vol 21 No 4, pp 379 - 387 , 2010.

[5]. ChenGuo, Xin, Yi Chen, Zhou, Wei Ge, Hong, ChunLiang, Yan, "Short-Term Load Forecasting Using Neural Network With Principal ComponentAnalysis", Proceedings of the Third International Conferenceon Machine Learning and Cybernetics, pp 3365 3369, 2004.

[6]. Chouw, Mo-Yuen, Zhu, Jinxiang, Tram, Hahn "Application of FuzzyMulti-Objective DecisionMaking in Spatial Load Forecasting“, IEEE Transactionon Power System Vol 13 No. 3, pp1185 - 1189, 1998. 
[7]. Committee on Electricity in Economic Growth, "Electricity in Economic Growth", National Academy Press, Washington DC, pp 1 - 13, 1986

[8]. Creswell, John.W, "Research Design, Qualitative, Quantitative and Mixed Methods Approaches “, Second Edition, Sage Publications, pp 3-23, 2003.

[9]. D. Darwanto, S. Sasmono, N. I. Sinisuka, M. W. Atmopawiro, "The Concept of Macro Demand Spatial Approach (MDSA) on Spatial Demand Forecasting for Main Development Area in Transmission Planning" (accepted publish in Journal of Energy and Power Engineering at 2014).

[10]. Ghods, L, Kalantar, M, "Different Methods of Long Term Electric Load Demand Forecasting ; A Comprehensive Review", Iranian Journal of Electrical and Electronic Engineering Vol 7 No 4, pp 249 - 259, 2011.

[11]. Ghods, L, Kalantar, M, “ Methods for Long-Term Electric Load Demand Forecasting A Comprehensive Investigation", IEEE International Conference on Industrial Technology, 2008.

[12]. Goodchild, Michael F, “A Geographer Looks at Spatial Information Theory”, SpringerVerlag Berlin Heidelberg, pp 1 - 12, 2001

[13]. Gorr, Wilpen, Johnson, Michael, Roehrig, Stephen (2001), "Point Demand Forecasting", H. John. Heinz III School of Public Policy and Management, Carnegie Melon University, Pittsburgh, pp 1 - 30, 2001

[14]. Hyndman, Rob J, "Density Forecasting for Long-Term Peak Electricity Demand", IEEE Transactions on Power System Vol 25 No 2, pp 1142 - 1152, 2010

[15]. Jain, Amit, Jain, M. Babita, "A Novel Hybrid Method for Short Term Load Forecasting using Fuzzy Logic and New Particle Swarm Optimization (NPSO)", 16th National Power System Conference, pp 132 - 138, 2010.

[16]. Kementerian Koordinator Bidang Perekonomian Republik Indonesia, "Masterplan Percepatan dan Perluasan Pembangunan Ekonomi Indonesia 2011 - 2025”, Jakarta, 2011, pp $51-73$

[17]. Lee Wilis,"Spatial Electric Load Forecasting 2nd edition", Marcel Dekker Inc, New York, pp 1-5, 2002.

[18]. Melo, J. D, Carreno, E. M, Padilha-Fetrin, A, "Multi-Agent Framework for Spatial Load Forecasting", 2011 IEEE Power and Energy Society General Meeting, pp 1-8, 2011

[19]. Melo, JD, Carreno, E.M, Padilha-Fetrin, A, "Spatial Load Forecasting Using A Demand Propagation Approach", IEEE/PES Transmission and Distribution Conference and Exposition: Latin America (T\&D-LA), pp 1-8, 2011

[20]. Presidential Decree No. 13/2012 on Spatial and Regional Planning at Sumatera,

[21]. S. Sasmono, N. I. Sinisuka, M. W. Atmopawiro, "Alternative Spatial Approach on Spatial Demand Forecasting for Transmission Expansion Planning", Proceeding of 2012 IEEE International Conference on Condition Monitoring and Diagnosis Volume 2, pp 577 580,2012

[22]. S. Sasmono, N. I. Sinisuka, M. W. Atmopawiro, "Macro Demand Spatial Approach (MDSA) with Principal Component Analysis (PCA) on Spatial Demand Forecasting for Industrial Area in Transmission Planning", Proceeding of 2013 IEEE International Conference on Information Technology and Electrical Engineering, pp 390 - 393, 2013

[23]. S. Sasmono, N. I. Sinisuka, M. W. Atmopawiro, D. Darwanto, "Macro Demand Spatial Approach (MDSA) Combined with Principal Component Analysis and Qualitative Analysis on Spatial Demand Forecasting for Main Development Area in Transmission Planning " Proceeding of The 5th IEEE PES (Power and Energy Society) Asia-Pacific Power and Energy Engineering Conference (APPEEC 2013)

[24]. Stoll, Harry G, "Least-Cost Electric Utility Planning", John Wiley \& Sons, 1989, pp 193 $-195$.

[25]. Tao Hong, "Long-Term Spatial Load Forecasting”, Thesis Manuscript, North Carolina State University, $13-70,2008$. 
[26]. Von Wormer," Some Aspects of Distribution Load Area Geometry ", Power Apparatus and Systems Vol 73, No 2 1954, pp 1343 - 1349.

[27]. Wei, Li, Ning Yan, Zhengang Zhang, " Study on Long-term Load Forecasting of MIXSVM Basedon Principal Component Analysis, International Conference on Future Biomedical Information, pp 439-441, 2009.

[28]. Yang Tao, Hillier, Bill, "The Fuzzy Boundary: The Spatial Definition Of Urban Areas “, Proceedings of 6th International Space Syntax Symposium, Istanbul, pp 091. 01 091.016, 2007

[29]. Yingying Li, DongxiaoNiu, "Application of Principal Component Regression Analysis in Power Load Forecasting for Medium and Long Term", 3rd International Conference on Advanced Computer Theory and Engineering, pp 201 - 203, 2010

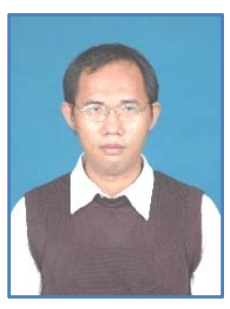

Sudarmono Sasmono received the B.S degree from Institut Teknologi Bandung, Indonesia in 1999, M.Eng degree from Institut Teknologi Bandung in 2010. Currently, he is Doctoral student at School of Electrical Engineering and Informatics, Institut Teknologi Bandung. His main interest is power system planning, smart grid and renewable energy, probabilistic, risk analysis and decision making in power system.

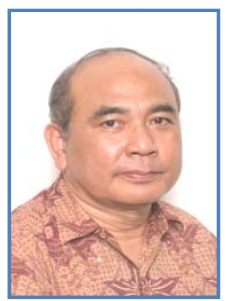

Ngapuli Irmea Sinisuka received the B.Eng degree from Institut Teknologi Bandung, Indonesia in 1974, M.Eng degree from Institute National Polytechniquede Grenoble, France in 1978.Ph.D degree from Universite Paul Sabatier-Toulouse, Prancis. Currently, he works as Professor at School of Electrical Engineering and Informatics, Institut Teknologi Bandung. His main interest is risk engineering, maintenance technique, and material insulation technique

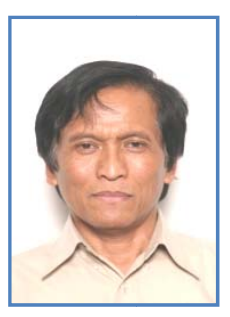

Mukmin Widyanto Atmopawiro received the B.Eng degree from Institut Teknologi Bandung, Indonesia in 1977, M. Eng degree from De Universite Louis Pasteur de Strasbourg I, France in 1987, and PhD degree from De Universite Louis Pasteur de Strasbourg I, France in 1992. Currently, he works as associated Professor at School of Electrical Engineering and Informatics, Institut Teknologi Bandung. His main interest is hydropower plant.

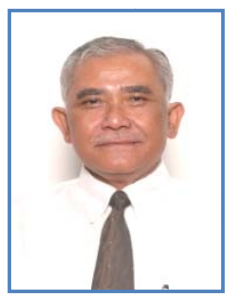

Djoko Darwanto received B. Eng degree and Ph. D degree from Institut Teknologi Bandung, Indonesia. Currently, he works as associated Professor at School of Electrical Engineering and Informatics, Institut Teknologi Bandung. His main interest is electromagnetic compatibility. 